\title{
OCUPACIONES RESIDENCIALES Y ENTIERROS HUMANOS EN NEGRO MUERTO 3 (VALLE DEL RÍO NEGRO, NORPATAGONIA)
}

\author{
LUCIANO PRATES, ALEJANDRO SERNA*, EMILIANO MANGE", LAURA LÓPEZ", \\ VICTORIA ROMANO", MAITÉN DI LORENZO"*, DANIELA SAGHESSI" \& LUCIO GONZÁLEZ V."*
}

\section{RESUMEN}

En este trabajo se presentan los resultados del estudio del conjunto arqueológico del sitio Negro Muerto 3, ubicado en el sector norte de la cuenca media del río Negro (provincia de Río Negro, Argentina). En el marco de actividades de rescate arqueológico se obtuvieron restos óseos humanos (NMI=12), artefactos líticos, restos faunísticos y alfarería. Se definió un mínimo de dos ocupaciones residenciales (fechadas entre 900 y 1.300 años Cal. AP) y una ocupación vinculada con actividades mortuorias (para el único entierro datado se obtuvo una edad de 950 años Cal. AP). Las características de la tecnología lítica (producción y uso expeditivo de artefactos confeccionados sobre rocas locales) y el patrón de explotación de los recursos (consumo de bajo número de vertebrados grandes y medianos, y de una alta diversidad de especies menores de hábitats acuáticos y/o ribereños) son congruentes con lo observado en sitios similares de la misma cuenca. Entre los aspectos más destacables y novedosos del sitio debe mencionarse el registro de Zea mays en tártaro dental, con una edad probable de 950 años Cal. AP. La presencia de esta especie doméstica fue interpretada como producto de su ingreso al área desde sectores occidentales de Norpatagonia y no como resultado de su cultivo en el ámbito local.

PALABRAS CLAVE: ocupaciones residenciales, entierros humanos, Zea mays, Holoceno tardío, Noreste de Patagonia.

\section{RESIDENTIAL OCCUPATIONS AND HUMAN BURIALS AT NEGRO MUERTO 3 SITE (NEGRO RIVER VALLEY, NORPATAGONIA)}

\footnotetext{
ABSTRACT

This paper presents the results of the study of Negro Muerto 3, located in the northern sector of the middle basin of the Negro River (Río Negro province, Argentina). This site is located on the left bank of the

* Consejo Nacional de Investigaciones Científicas y Técnicas. División Arqueología, Facultad de Ciencias Naturales y Museo, Universidad Nacional de La Plata. Paseo del Bosque s/n. La Plata. $\$ lprates@fcnym.unlp.edu.ar, aserna@fcnym.unlp.edu.ar, emilianomange@ gmail.com, mllopezdepaoli@yahoo.com.ar.

* Facultad de Ciencias Naturales y Museo, Universidad Nacional de La Plata. Paseo del Bosque s/nº. La Plata. viki-romano@hotmail. com, maiten.dilorenzo@gmail.com, danisaghessi@hotmail.com

*** Centro Regional de Investigaciones Científicas y Transferencia Tecnológica (CRILAR-CONICET). luciogonzalezvenanzi@gmail.com
} 
Negro river valley, Northern Patagonia, Argentina. In the frame of preventive archaeology tasks, human remains $(\mathrm{MNI}=12)$, lithics, faunal remains, and pottery sherds were recovered. Based on the materials analysis a minimun of two residential occupations were defined (dated between ca. 900 and 1300 cal. years $\mathrm{BP}$ ), and one occupation associated to mortuary practices (the only dated skeleton gave an age of ca. 950 cal. years BP). The main trends observed on the base of lithic technology analysis (production and use of expedient tools made on local raw material" por "use of expedient tools on local raw material), and faunal remains analysis (exploitation of low number of big and middle sized vertebrates, and exploitation of a high diversity of small sized riparian/aquatic fauna) are similar to those observed at other archaeological sites of the area. One of the highligts of this paper is the record of Zea mays in dental calculus, with a probable age of ca. 950 cal. years BP. The presence of this domestic species was interpreted as a result of its importation from Northwestern Patagonia, and not as a result of its local cultivation.

KEY WORDS: residential occupations, human burials, Zea mays, Late Holocene, Northeast Patagonia.

\section{INTRODUCCIÓN}

La asociación espacial entre áreas residenciales y mortuorias es un rasgo característico de la ocupación humana del valle del río Negro durante el Holoceno tardío. Esta asociación ha sido observada desde las primeras descripciones arqueológicas en la segunda mitad del siglo XIX (Strobel, 1867; Moreno, 1876), y retomada y ratificada en investigaciones más recientes (Moldes de Entraigas, 1983; Peronja et al. 1987; Fisher \& Nacuzzi, 1992; Prates et al. 2010a; Prates et al. 2011; Serna \& Prates, 2012). Aunque este patrón ha sido interpretado de diferentes maneras, la convivencia de entierros y sitios residenciales no habría sido el producto de los mismos eventos de ocupación, sino de la recurrencia en el uso de los mismos espacios para fines diversos (Prates \& Di Prado, 2013). Aunque esta es la explicación más coherente con la información disponible hasta ahora, es necesario validarla con la incorporación de información arqueológica precisa, ya que de los numerosos sitios de este tipo conocidos para el área, sólo Loma de los Muertos (Prates et al. 2010a y b), La Victoria 5 (Prates et al. 2011), Negro Muerto 2 (Serna \& Prates, 2012), Pomona (Mange, 2019) y La Toma (Flensborg et al. 2018) han sido o están siendo estudiados de manera sistemática.

En este trabajo se presentan los resultados del estudio del sitio Negro Muerto 3 (NM3), que exhibe un patrón similar al observado en otros sitios del área, es decir, la convivencia de entierros humanos y evidencias de ocupación residencial en un mismo espacio. El sitio está ubicado dentro de la estancia homónima, sobre la margen norte del valle medio del río Negro (3948,762' S; 65²18,705' O), y a ca. $500 \mathrm{~m}$ al SO del sitio Negro Muerto 2 (Serna \& Prates, 2012) (Fig. 1). Los materiales analizados se encontraban sobre una pequeña elevación de arena de textura areno-fangosa que apoya sobre el manto de loess que recubre la mayor parte del valle. La ausencia de proxies asociados con un ambiente hídrico (e.g. diatomeas y espículas) sugiere que el depósito tiene un origen principalmente eólico (Mange et al. 2016).

El sitio se ubica contiguo a un canal de inundación del río y su hallazgo se produjo accidentalmente durante la realización de actividades de desmonte y nivelación en el año 2013. El propietario del establecimiento detectó elementos óseos en superficie y dio aviso al Museo Paleontológico de Lamarque. Mediante los trabajos de campo se recolectaron materiales superficiales de manera sistemática, se tomaron muestras de cuatro estructuras de combustión parcialmente expuestas y se excavaron dos áreas con entierros humanos. Una de las áreas, con dos esqueletos articulados (Individuos 1 y 2), se excavó durante la primera visita al sitio, y la otra, con dos esqueletos articulados (Individuos 3 y 4), uno parcialmente articulado (Individuo 5) y abundantes elementos óseos dispersos (correspondientes a por lo menos siete individuos), fue excavada en un segundo rescate. Los objetivos generales de este artículo son caracterizar el sitio, incluyendo la evaluación de los distintos tipos de registro (restos humanos, 


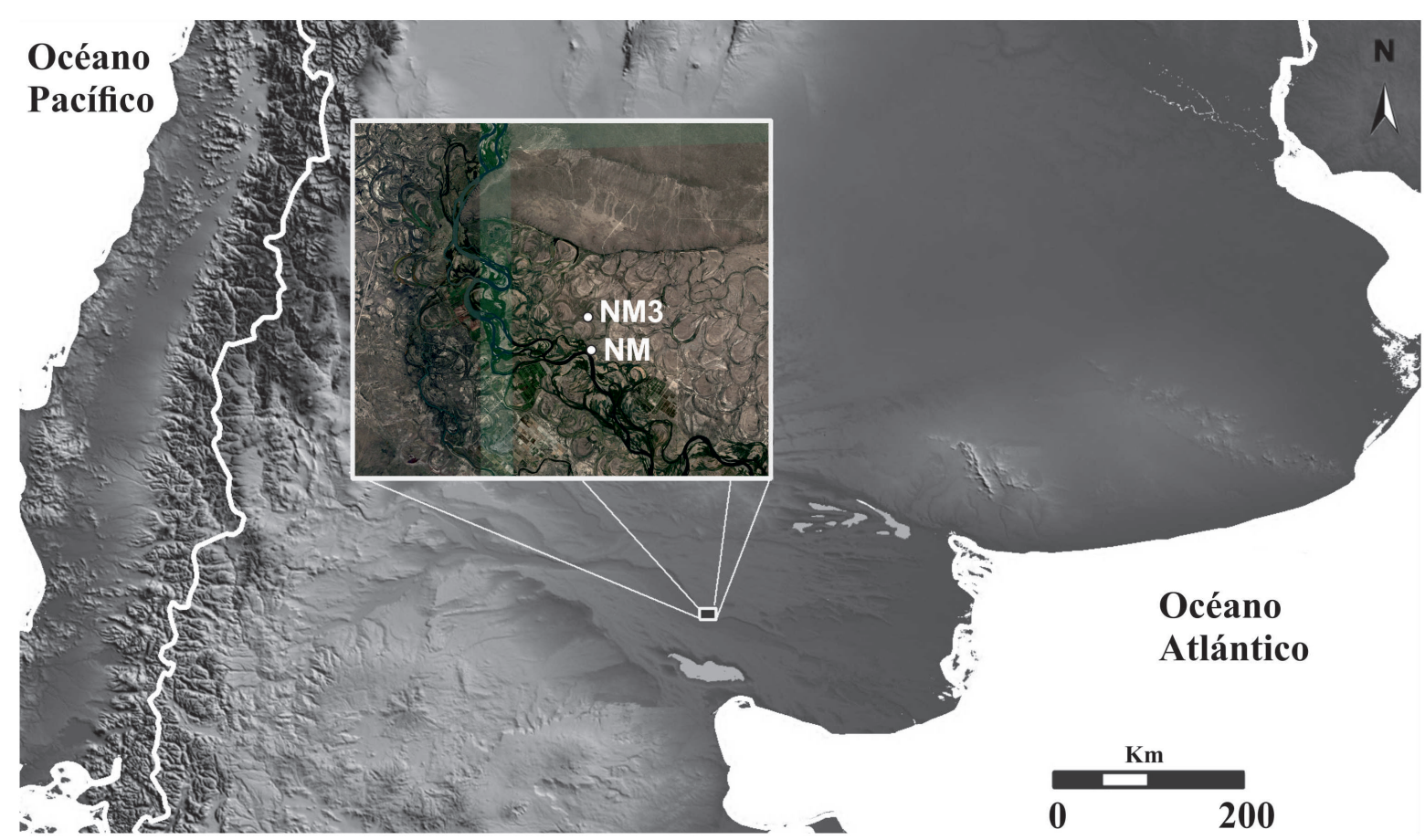

Fig. 1. Ubicación del sitio Negro Muerto 3.

artefactos líticos, restos faunísticos y micro-restos vegetales) y discutir sus implicancias a nivel regional. Los resultados del estudio de los restos faunísticos se presentan resumidamente porque ya han sido publicados en un trabajo previo (Mange et al. 2016) y los de la cerámica no se incluyen porque están en proceso de análisis.

\section{MATERIALES Y MÉTODOS}

Los materiales analizados fueron recuperados mediante recolecciones superficiales y excavaciones. Las primeras incluyeron la recolección de la totalidad de restos -principalmente humanos, faunísticos, líticos y cerámicos- visibles en el área de exposición del sitio (ca. $3250 \mathrm{~m}^{2} ; 65$ x $50 \mathrm{~m}$ ), que coincidía con la pequeña elevación de origen eólico cuya nivelación expuso el conjunto. Las excavaciones fueron efectuadas exclusivamente en el lugar en que la maquinaria había removido y expuesto restos humanos. En el caso de los microrestos vegetales (silicofitolitos, granos de almidón y tejido celular no mineralizado), se analizaron muestras atrapadas en el cálculo o tártaro dental.

La representación anatómica de los esqueletos humanos excavados y la completitud de cada individuo fueron ilustradas mediante osteogramas, mientras que los recuperados en superficie se cuantificaron y analizados de acuerdo con cohortes etarios. La determinación sexual y la estimación etaria se realizaron en base a rasgos diagnósticos de distintos elementos y siguiendo las propuestas de Buikstra \& Ubelaker (1994) (véanse también Merchant \& Ubelaker, 1977; Scheuer \& Black, 2000; White \& Folkens, 2005). El relevamiento de variables tafonómicas, naturales y antrópicas, se efectuó a través de la inspección macroscópica de las superficies óseas (Lyman, 1994; Gutiérrez, 2004; González, 2012). Se realizó una inspección morfoscópica de las bóvedas craneanas a fin de determinar la presencia de modificaciones morfológicas de origen cultural (Dembo \& Imbelloni, 1938).

La identificación anatómica y taxonómica de los restos faunísticos fue realizada mediante la consulta a colecciones osteológicas de referencia (sección Mastozoología, FCNyM-UNLP) y el uso de atlas osteológicos (e.g. Sierpe, 2015). Los mamíferos indeterminados se organizaron en categorías según el peso corporal (sensu Redford \& Eisenberg, 1992). Para la cuantificación se utilizaron medidas de abundancia standard (Binford, 
1981; Grayson, 1991; Mengoni Goñalons, 1999) y para el estudio tafonómico los lineamientos de varios autores (para vertebrados grandes: Behrensmeyer, 1978; Lyman, 1994; Mengoni Goñalons, 1999; para vertebrados chicos: Andrews, 1990; Fernández-Jalvo \& Andrews, 1992; Gutiérrez, 2004; Fernández et al. 2011; Medina et al. 2012). Las cáscaras de huevo fueron determinadas y analizadas según los criterios de Apolinaire \& Turnes (2010) y los moluscos según Prates \& Marsans (2007).

El análisis de los artefactos líticos de filo se llevó a cabo siguiendo los lineamientos de Aschero (1975, 1983), Aschero \& Hocsman (2004), y el de los artefactos de molienda según Babot (2004) y Matarrese (2015). Debido a las características de las materias primas de los artefactos tallados y a las dificultades para su determinación precisa en muestra de mano, las mismas se agruparon en categorías generales (Prates, 2008).

Para la toma de muestras de microrestos vegetales se raspó el tártaro mediante un instrumento de acero punzante y se montó directamente sobre portaobjeto con aceite de inmersión. El análisis se realizó bajo microscopio óptico en luz clara y campo polarizado a 400X y los micro-restos fueron clasificados según sus características cuali-cuantitativas siguiendo el ICPN (Madella et al. 2005) para fitolitos e ICSN (2011) para almidones. Para la clasificación e identificación se emplearon colecciones de referencia propias depositadas en el Laboratorio 129 de la División Arqueología (FCNyM, Universidad de La Plata) y bibliografía específica (Reichert, 1913; Twiss et al. 1969; Zucol, 1996, 1998, 1999, 2000, 2001; Korstanje \& Babot, 2007; entre otros).

\section{RESULTADOS}

\section{Los restos óseos humanos}

Como fue señalado, los Individuos 1 y 2 fueron excavados durante la primera campaña y los Individuos 3, 4 y 5 durante una campaña posterior, a pocos metros de distancia de los anteriores. En todos los casos la matriz sedimentaria que contenía a los entierros presentaba distintos tipos de materiales arqueológicos: fragmentos de valva de Diplodon sp., desechos líticos y tiestos. Estos materiales se encontraban a distintas profundidades, dispersos de manera homogénea en el área de excavación y no presentaban un patrón espacial claro. Aunque las bóvedas craneanas presentan un leve achatamiento en el sector de lambda, que se observa más pronunciado por el prominente desarrollo de la escama occipital de los cráneos, ninguno muestra señales evidentes de haber sido modificado por prácticas culturales.

$\underline{\text { Individuo } 1}$

El Individuo 1 es un adulto joven (21 a 23 años aproximadamente) de sexo masculino (Tabla 1). El cráneo, la mandíbula y algunos elementos postcraneales estaban parcialmente expuestos y desarticulados debido a una remoción reciente. El resto del esqueleto se encontraba articulado, en posición decúbito dorsal con los miembros inferiores flexionados y orientado hacia el Norte. Con excepción de algunas vértebras, carpos, metacarpos y metatarsos, el esqueleto está prácticamente completo (Fig. 2), aunque presenta alto grado de fractura post-depositacional (61\%). El $97 \%$ de los elementos presenta depósitos de carbonato de calcio, el $48 \%$ óxido de manganeso y el $95 \%$ marcas de raíces (Tabla 1). En la matriz sedimentaria que contenía al I1 se registraron seis fragmentos de valvas de Diplodon chilensis y dos desechos de talla lítica a distinta profundidad.

\section{Individuo 2}

El Individuo 2 es un adulto medio (35 a 39 años aproximadamente) de sexo masculino (Tabla 1). Estaba ubicado a $55 \mathrm{~cm}$ del anterior y fue enterrado con la misma orientación, mirando hacia el Este, y a una profundidad similar. El esqueleto estaba completamente articulado y dispuesto en posición decúbito lateral izquierdo con los miembros superiores e inferiores flexionados. El grado de representación anatómica es elevado, no habiéndose hallado falanges y algunos elementos del carpo (Fig. 2), y unos pocos elementos están fracturados post-depositacionalmente (28\%). La mayor parte del material óseo presenta depositaciones de carbonato de calcio (99\%) y marcas de raíces (88\%), mientras que el $34 \%$ muestra depósitos de óxido de manganeso (Tabla 
1). Como en el Individuo 1, se registraron en los sedimentos circundantes tres fragmentos de valvas de $D$. chilensis y tres desechos de talla lítica. Estos materiales se encontraban a distinta profundidad, dispersos de manera homogénea en el área de excavación y no presentaban un patrón espacial claro.

\section{Individuo 3}

Los Individuos 3, 4 y 5 fueron hallados varios meses después que los anteriores y en un sector contiguo al área de excavación previa (unos tres metros al ONO). El Individuo 3 es un adulto medio (35 a 45 años aproximadamente) de sexo masculino (Tabla 1), enterrado con orientación SSE y mirando hacia el Este. El esqueleto estaba completamente articulado, en posición decúbito dorsal con los miembros inferiores y superior derecho flexionados. La representación anatómica es alta, faltan principalmente costillas y falanges (Fig. 2), y la fracturación de los restos moderada (51\%). Un $77 \%$ de los elementos presenta carbonato de calcio, un $37 \%$ óxido de manganeso y un $97 \%$ marcas de raíces (Tabla 1 ). En la matriz de sedimentos también se hallaron un desecho de talla, un fragmento de alfarería lisa y dos fragmentos de valva de D. chilensis. Estos materiales no presentan un patrón espacial claro. A partir de este individuo se obtuvo un fechado de $1.091 \pm 35$ años ${ }^{14} \mathrm{C}$ AP [906-1001 cal. AP] (AA105420, costilla).

\section{Individuo 4}

El Individuo 4 es un adulto medio (30 a 39 años aproximadamente) de sexo masculino (Tabla 1), enterrado a $82 \mathrm{~cm}$ al SO del Individuo 3 pero orientado en sentido opuesto (al NNO) y mirando hacia el Este. El esqueleto estaba completamente articulado y dispuesto decúbito lateral izquierdo con los miembros inferiores flexionados. La representación anatómica es elevada, sólo faltan algunas costillas, falanges y elementos del tarso (Fig. 2), y el grado de fracturación moderado (47\%). La mayoría de los elementos presenta carbonato de calcio y marcas de raíces $199 \%$ en ambos casos) y un $51 \%$ óxido de manganeso (Tabla 1). Se registraron dos fragmentos de valva de $D$. chilensis, un fragmento de alfarería lisa y un desecho de talla lítica.

\section{Individuo 5}

El Individuo 5, un adulto medio (35 a 39 años aproximadamente) de sexo femenino (Tabla 1), se encontraba equidistante (a unos $85 \mathrm{~cm}$ al SO), orientado al SSE y mirando al Oeste. El esqueleto fue afectado por los movimientos de tierra y sólo se mantuvieron en posición anatómica los miembros superiores, las clavículas, las escápulas, parte de la columna vertebral y la cintura pélvica. La posición del esqueleto era decúbito dorsal. La representación anatómica del conjunto es baja, faltan todos los huesos largos de los miembros inferiores, varios carpos, tarsos, falanges y costillas (Fig. 2), y los elementos presentes tienen un elevado porcentaje de fracturación post-depositacional (64\%). Además, el $91 \%$ presenta carbonato de calcio, el $74 \%$ óxido de manganeso y el $98 \%$ marcas de raíces (Tabla 1 ).

\section{$\underline{\text { Restos humanos superficiales }}$}

Los resultados detallados del análisis de los restos humanos hallados en superficie son parte de otro trabajo (Serna \& Romano, 2018), por lo que aquí sólo se retoman de forma sucinta sus características principales. Los especímenes óseos dispersos en superficie y semienterrados fueron analizados en su totalidad $(n=275)$ y agrupados según categorías de edad. A partir de este registro se calculó la presencia de al menos siete individuos (NMI=7): dos infantes (ambos masculinos), dos niños (uno masculino y uno indeterminado) y tres adultos (dos masculinos y uno femenino) (Tabla 1, véase también Serna \& Romano, 2018). Aunque estos restos están altamente fracturados post depositacionalmente, la mayoría presenta un grado de completitud buena o muy buena. Con respecto a las depositaciones químicas, todos los especímenes presentan carbonato de calcio y cerca de la mitad de la muestra, motas de óxido de manganeso. La mayoría tiene marcas de raíces, mientras que el deterioro químico y las marcas de roedores son escasas (Serna \& Romano, 2018). 


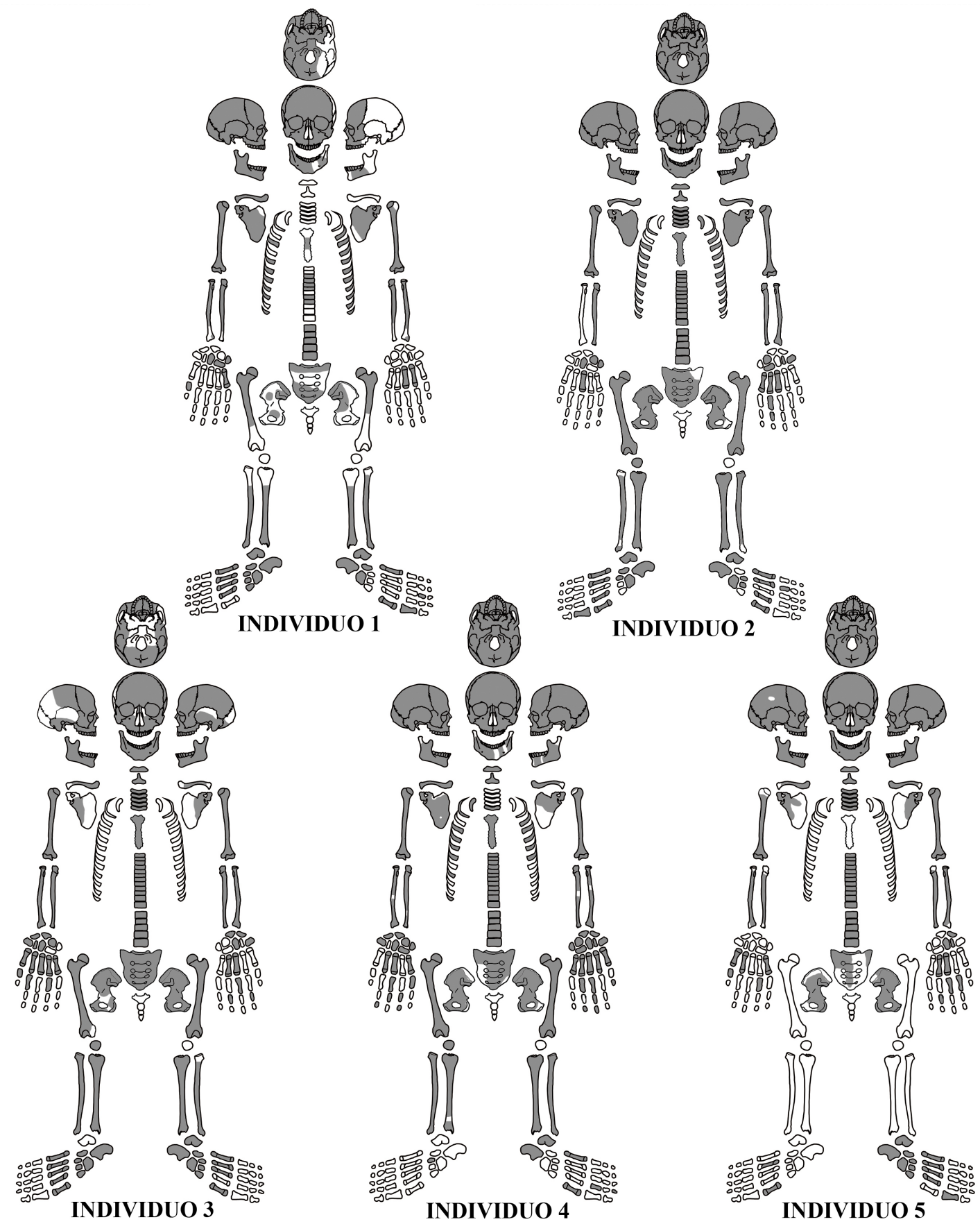

Fig. 2. Representación de elementos óseos de los Individuos 1, 2, 3, 4 y 5.

Micro-restos vegetales en cálculo dental

Se tomaron muestras en los tres individuos de NM3 que presentaban depósitos de cálculo dental (Individuos 2, 4 y 5). El análisis microscópico de esas muestras permitió identificar silicofitolitos y granos de almidón en todos ellos (Tabla 2). Entre las observaciones más relevantes pueden mencionarse: a) registro de fitolitos cono truncado de $20 \mu \mathrm{m}$ con ápice ondulado y base plana correspondientes con 
Tabla 1. Información sexo-etaria y tafonómica de los individuos rescatados en el sitio NM3. Nota: $\widehat{\delta}$ : masculino; : : femenino; Ø: indeterminado. $\mathrm{CaCO}_{3}$ : carbonato de calcio; $\mathrm{MnO}_{2}$ : óxido de manganeso.

\begin{tabular}{|c|c|c|c|c|c|c|c|c|}
\hline \multirow{2}{*}{ Individuo } & \multirow{2}{*}{ Edad } & \multirow{2}{*}{ Sexo } & \multirow{2}{*}{$\begin{array}{l}\text { Posición } \\
\text { (decúbito) }\end{array}$} & \multirow{2}{*}{ Orientación } & \multicolumn{4}{|c|}{ Variables Tafonómicas } \\
\hline & & & & & Fractura & $\mathrm{CaCO}_{3}$ & $\mathrm{MnO}_{2}$ & Raíces \\
\hline Ind. 1 & adulto joven & $\hat{0}$ & dorsal & $\mathrm{N}$ & $61 \%$ & $97 \%$ & $48 \%$ & $95 \%$ \\
\hline Ind. 2 & adulto medio & $0^{\lambda}$ & lateral & $\mathrm{N}$ & $28 \%$ & $99 \%$ & $34 \%$ & $88 \%$ \\
\hline Ind. 3 & adulto medio & $\hat{o}$ & dorsal & SSE & $51 \%$ & $77 \%$ & $37 \%$ & $97 \%$ \\
\hline Ind. 4 & adulto medio & $\widehat{0}$ & lateral & NNO & $47 \%$ & $99 \%$ & $51 \%$ & $99 \%$ \\
\hline \multirow[t]{2}{*}{ Ind. 5} & adulto medio & 우 & dorsal & SSE & $64 \%$ & $91 \%$ & $74 \%$ & $98 \%$ \\
\hline & $\begin{array}{l}\text { infante } \\
(\mathrm{NMI}=2)\end{array}$ & $\lambda, \hat{0}$ & - & - & $43 \%$ & $100 \%$ & $57 \%$ & $100 \%$ \\
\hline \multirow[t]{2}{*}{$\begin{array}{l}\text { Recolección } \\
\text { superficial }\end{array}$} & $\begin{array}{c}\text { niño } \\
(\mathrm{NMI}=2)\end{array}$ & $\delta, \varnothing$ & - & - & $38 \%$ & $100 \%$ & $44 \%$ & $100 \%$ \\
\hline & $\begin{array}{l}\text { adulto } \\
(\mathrm{NMI}=3)\end{array}$ & $\hat{0}, \hat{o}$, , & - & - & $80 \%$ & $100 \%$ & $65 \%$ & $99 \%$ \\
\hline
\end{tabular}

el morfotipo wavy top-rondel (Bozarth, 1993; Piperno, 2006) en el Individuo 4, identificado como afín a la mazorca de maíz (Zea mays L.) (Fig. $3)$; b) registro de numerosos granos de almidón de diferentes morfologías en la muestra del Individuo 4 , de los cuales se destacan siete de morfología facetada, con hilo puntiforme central y medidas entre 16 y $27 \mu \mathrm{m}$, afines a maíz (Z. mays) y uno de morfología irregular, con hilo filiforme de 24 $\mu \mathrm{m}$ de largo similar a los registrados para algarrobo (Prosopis sp.) (Fig. 3). Si bien la morfología de los granos de almidón muchas veces puede plantear ambigüedad para la identificación de Zea mays y Prosopis sp. (Giovannetti et al. 2008), la evidencia recuperada del Individuo 4 corresponde a una asociación de micro-restos compuestos por fitolitos diagnósticos de maíz junto a almidones de morfología asimilable a dicha especie. Esto permite proponer su ingesta por parte del Individuo 4; c) registro de fitolitos asignados a la familia Poaceae sin identificación específica, en los Individuos 2, 4 y 5 y d) registro de almidones de morfología irregular, hilo filiforme en posiciones tanto céntrica como excéntrica, medidas hasta $28 \mu \mathrm{m}$ y presencia en algunos granos de protuberancias, identificados como afines a los frutos de algarrobo (Prosopis sp.) en la muestra del Individuo 5.

\section{Análisis de restos faunísticos}

El conjunto faunístico de NM3 está constituido por restos óseos y dentales, valvas de moluscos y cáscaras de Rhea sp. (Mange et al. 2016). Se registró una alta diversidad taxonómica (Tabla 3) que incluye principalmente restos de mamíferos -grandes, medianos y pequeños (Fig. 4)-, en menor medida de moluscos y aves, y escasos de reptiles y peces. Se observaron evidencias claras de acción antrópica (huellas de corte, impacto, raspado y/o formatización) en mamíferos grandes

Tabla 2. Micro-restos vegetales obtenidos en muestras de cálculo dental de NM3

\begin{tabular}{ccccccccc}
\cline { 2 - 9 } & \multicolumn{3}{c}{ Silicofitolitos } & \multicolumn{5}{c}{ Granos de almidón } \\
\hline Muestra & Poaceae & Zea mays & N.I & Total & cf. Prosopis sp. & cf. Zea mays & N.I & Total \\
\hline IND. 2 & 23 & 0 & 16 & 39 & 0 & 0 & 0 & 0 \\
IND. 4 & 121 & 6 & 120 & 247 & 1 & 9 & 7 & 17 \\
IND. 5 & 28 & 0 & 30 & 58 & 3 & 0 & 3 & 6 \\
\hline
\end{tabular}


y medianos, artiodáctilos, L. guanicoe (guanaco), $O$. bezoarticus (venado de las pampas), $D$. patagonum (mara), C. villosus (peludo), roedores indeterminados (Galea leucoblephara), rheidos, aves medianas y D. chilensis (almeja de río); y evidencias ambiguas (evidencias de combustión $y / o$ fractura en fresco) en mamíferos grandes $e$ indeterminados, milodontinos, artiodáctilos, $L$. guanicoe, $O$. bezoarticus, D. patagonum, $M$. coypus (coipo), Z. pichiy, C. villosus, roedores indeterminados, Caviinae indet., Ctenomys sp., Rhea sp., aves medianas, peces, cáscaras de huevo de ñandú y los moluscos fluviales $D$. chilensis y $C$. gibbosa. En el caso del milodontino (probablemente Mylodon sp.), aunque no presenta marcas antrópicas y no es contemporáneo a la ocupación del sitio, su presencia en un contexto sedimentario tardío implica necesariamente su introducción en el sitio por la acción humana (Mange et al. 2016). Desde el punto de vista tafonómico, los restos óseos presentan principalmente marcas de raíces $(63,5 \%)$ y depósitos corticales de carbonato de calcio (53\%). El conjunto óseo presenta una baja incidencia de meteorización (14\%), la cual corresponde en su mayoría al estadio 1 (sensu Behrensmeyer, 1978). Este perfil de meteorización es compatible con una breve y escasa exposición aérea del conjunto. A partir del conjunto faunístico se obtuvieron dos fechados radiocarbónicos: 1430 \pm 70 años ${ }^{14} \mathrm{C}$ AP [1171-1426 cal. AP] (LP3219, tibia de L. guanicoe) y $1110 \pm 33$ años ${ }^{14} \mathrm{C}$ AP [924-999 cal. AP] (AA106437, falange de O. bezoarticus).

\section{Análisis de los artefactos líticos}

El conjunto lítico está constituido por 136 artefactos, de los cuales el 98,5\% fue tallado sobre rocas volcánicas y silíceas. Predominan los desechos de talla $(\mathrm{n}=99)$, seguidos por los instrumentos $(n=28)$ y los núcleos $(n=9)$. Las lascas internas predominan sobre las externas y entre las primeras prevalecen las de rocas silíceas. La mayor parte de los núcleos descartados en el sitio es resultado de la talla de rodados $(n=8)$ y, entre ellos, predominan las formas no estandarizadas $(n=7$; dos de lascados aislados, dos bifaciales irregulares, uno amorfo, uno poliédrico y uno globuloso). Es interesante que los únicos estandarizados (uno

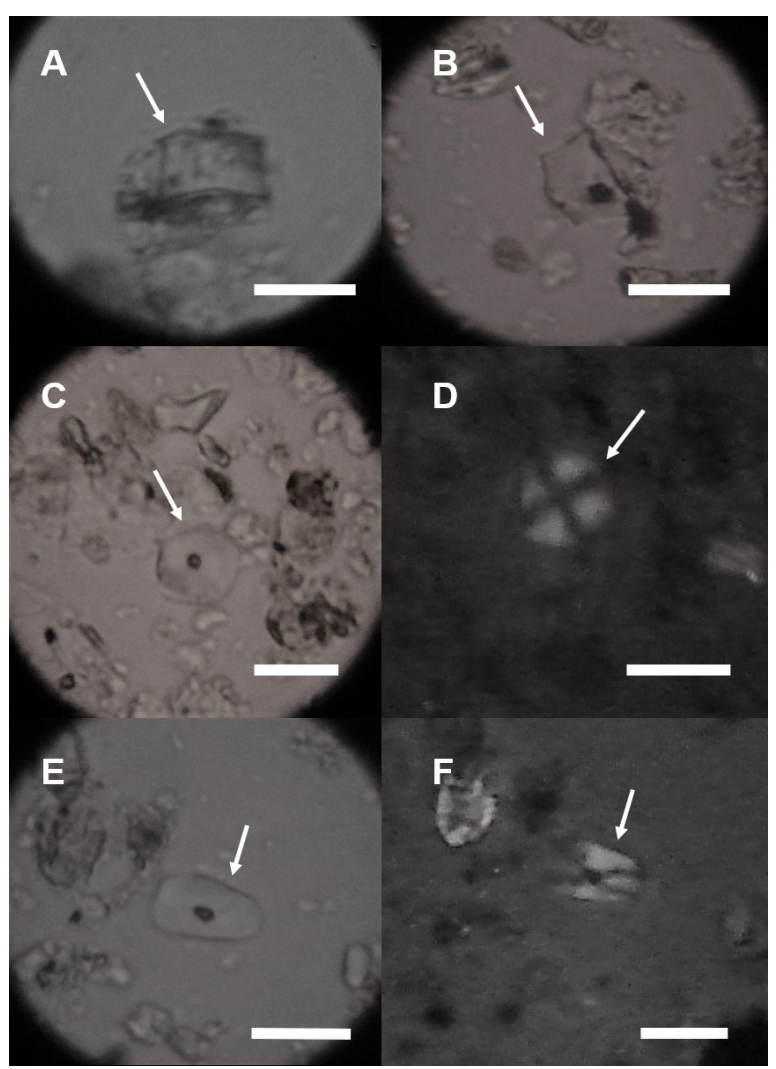

Fig. 3. Micro-restos vegetales de tártaro dental obtenidos de muestras de NM3. A-B Silicofitolitos de Zea mays (maíz). C-D Grano de almidón de cf. Zea mays (maíz) bajo luz clara y polarizada respectivamente. E-F Grano de almidón de cf. Prosopis sp. (algarrobo) bajo luz clara y polarizada respectivamente. Escala $=20 \mu \mathrm{m}$.

bifacial regular y otro discoidal) están tallados sobre materias primas silíceas. Los instrumentos de NM3 son principalmente artefactos tallados $(n=26)$ que fueron confeccionados sobre materias primas silíceas $(n=19)$ e ígneas básicas $(n=7)$, y sólo dos modificados por picado, abrasión y/o pulido realizados sobre areniscas $(n=2)$. Entre los primeros predominan los instrumentos unifaciales marginales $(n=14)$, seguidos por los de adelgazamiento bifacial $(\mathrm{n}=5)$, parcialmente extendidos $(n=3)$, de reducción bifacial $(n=3)$ y bifaciales marginales $(n=1)$. Los grupos tipológicos más representados son los raspadores $(n=7)$, que presentan morfologías variadas (dos frontales cortos, dos frontales, uno perimetral, uno frontal largo y uno doble); las lascas retocadas $(n=4)$, los bifaces $(n=4)$, las puntas de proyectil $(n=4)$ (una 
Tabla 3. Representación taxonómica de los restos faunísticos de NM3.

$\mathrm{CO}=$ corte; $\mathrm{RA}=$ raspado; $\mathrm{IMP}=$ impacto; $\mathrm{FF}=$ fractura en fresco.

\begin{tabular}{|c|c|c|c|c|c|}
\hline \multirow{2}{*}{$\begin{array}{l}\text { Tipo de material/ Taxa } \\
\text { Restos óseos y dentales }\end{array}$} & \multirow{2}{*}{ NISP } & \multirow{2}{*}{ NMI } & \multicolumn{3}{|c|}{ Marcas tafonómicas } \\
\hline & & & Combustión & Procesamiento & Format. \\
\hline Mammalia indet. & 6 & $\mathrm{X}$ & $\mathrm{X}$ & & \\
\hline Mammalia indet. (grandes) & 67 & $\mathrm{X}$ & $\mathrm{X}$ & $\mathrm{CO} / \mathrm{FF}$ & \\
\hline Mammalia indet. (medianos) & 10 & $\mathrm{X}$ & & CO/IMP/RA & \\
\hline Mylodontinae indet. & 1 & 1 & $\mathrm{X}$ & & \\
\hline Artiodactyla indet. & 5 & 1 & $\mathrm{X}$ & $\mathrm{CO} / \mathrm{FF}$ & $\mathrm{X}$ \\
\hline Lama guanicoe & 97 & 3 & $\mathrm{X}$ & $\mathrm{CO} / \mathrm{IMP} / \mathrm{RA} / \mathrm{FF}$ & $\mathrm{X}$ \\
\hline Ozotoceros bezoarticus & 9 & 1 & $\mathrm{X}$ & $\mathrm{CO} / \mathrm{FF}$ & \\
\hline Carnivora indet. & 1 & $\mathrm{X}$ & & & \\
\hline Lycalopex sp. & 1 & 1 & & & \\
\hline Dolichotis patagonum & 3 & 1 & $\mathrm{X}$ & RA & \\
\hline Myocastor coypus & 2 & 1 & & FF & \\
\hline Dasipodidae indet. & 14 & $\mathrm{x}$ & $\mathrm{x}$ & & \\
\hline Chaetophractus villosus & 14 & 1 & $\mathrm{X}$ & $\mathrm{CO}$ & \\
\hline Zaedyus pichiy & 3 & 1 & $\mathrm{X}$ & & \\
\hline Rodentia indet. & 49 & $\mathrm{X}$ & $\mathrm{X}$ & $\mathrm{CO}$ & \\
\hline Caviinae indet. & 5 & 1 & $\mathrm{X}$ & & \\
\hline Microcavia australis & 1 & 1 & & & \\
\hline Galea leucoblephara & 12 & 4 & & $\mathrm{CO}$ & \\
\hline Ctenomys sp. & 9 & 4 & $\mathrm{X}$ & & \\
\hline Holochilus vulpinus & 10 & 5 & & & \\
\hline Rhea sp. & 7 & 1 & $\mathrm{X}$ & $\mathrm{CO} / \mathrm{FF}$ & \\
\hline Ave (mediana) indet. & 21 & 3 & $\mathrm{x}$ & $\mathrm{CO} / \mathrm{FF}$ & \\
\hline Chelonoidis chilensis & 1 & 1 & & & \\
\hline Osteichthyes indet. & 2 & 1 & $\mathrm{X}$ & & \\
\hline Subtotal & 350 & 32 & & & \\
\hline \multicolumn{6}{|l|}{ Restos de cáscara de huevo } \\
\hline Rhea sp. & 12 & $\mathrm{X}$ & $\mathrm{X}$ & & \\
\hline Rhea americana & 2 & (1) & & & \\
\hline Rhea pennata & 2 & (1) & & & \\
\hline \multicolumn{6}{|l|}{ Restos de valvas de moluscos } \\
\hline Volutidae indet. & 1 & 1 & & & \\
\hline Mytilidae indet. & 1 & 1 & & & \\
\hline Diplodon chilensis & 133 & 73 & $\mathrm{X}$ & & $\mathrm{X}$ \\
\hline \multirow[t]{2}{*}{ Chilina sp. } & 11 & 11 & $\mathrm{X}$ & & \\
\hline & 512 & 118 & & & \\
\hline
\end{tabular}




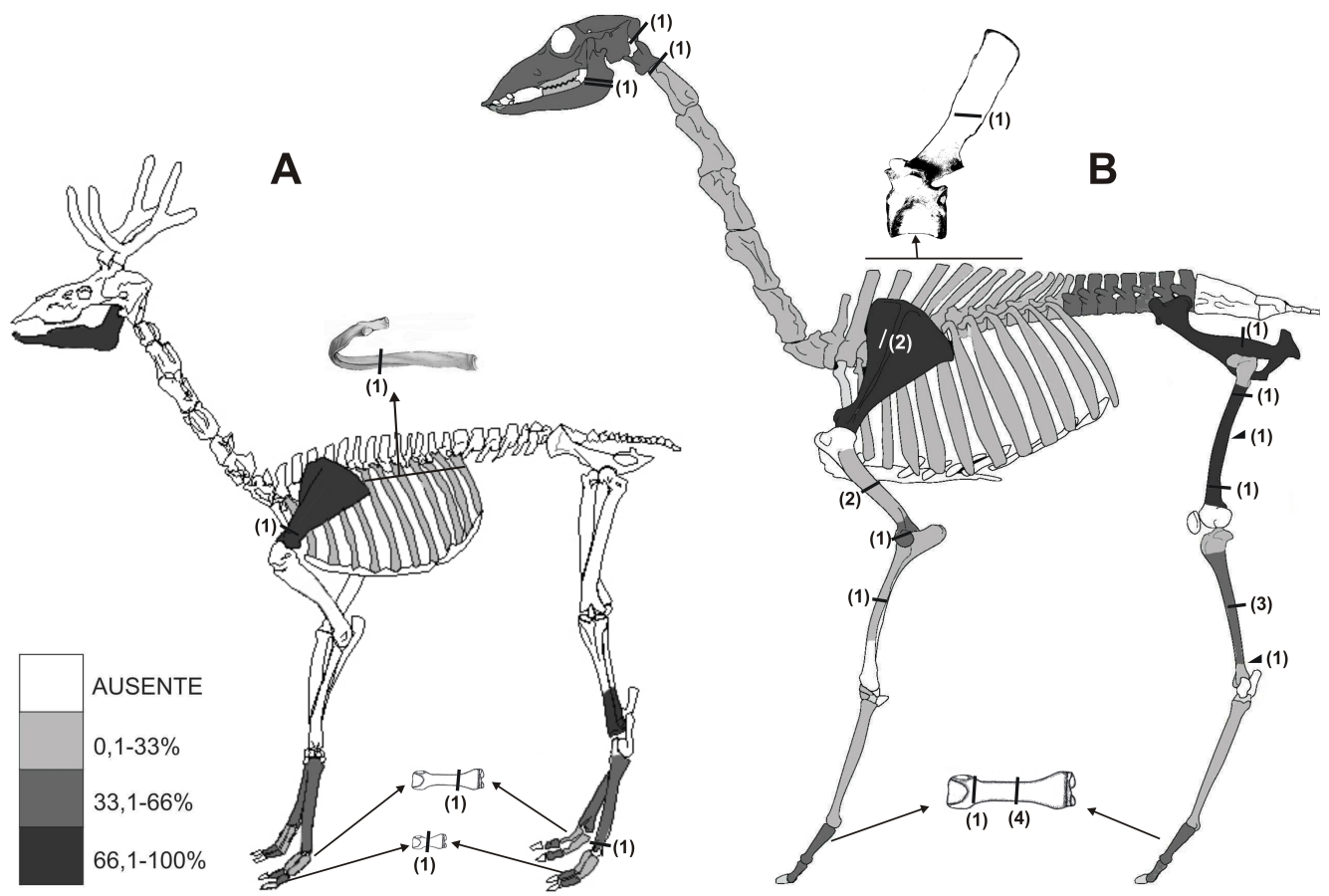

Fig. 4. Representación anatómica (MAU \%) de O. bezoarticus y L. guanicoe y ubicación de las huellas de corte (líneas), de raspado (doble líneas) y de impacto (triángulos).

triangular pequeña apedunculada y tres preformas), los cepillos $(n=2)$ y los perforadores $(n=1)$. Los fragmentos de artefactos de molienda de arenisca $(\mathrm{n}=2)$ son de tamaño pequeño y ambos presentan huellas de picado. Uno de ellos es un artefacto pasivo de molienda doble (posible molino) con dos superficies con rastros de uso (presenta desgaste por abrasión y estrías paralelas y perpendiculares al eje mayor de la pieza), y el otro es un borde de un artefacto pasivo mayor, con una superficie abradida por uso y estrías.

\section{DISCUSIÓN}

\section{Contexto, cronología y asociación espacial}

Además del impacto frecuente de las tareas de desmonte y nivelación sobre los sitios arqueológicos en el valle del río Negro, dos limitaciones importantes para su estudio son la dinámica a la que están sometidos y la baja resolución estratigráfica que generalmente presentan (Prates, 2008; Prates et al. 2010a). Esa dinámica, condición típica en el interior de valles fluviales (Brown, 1997), se relaciona con la acción de varios agentes, de manera que la integridad del conjunto (sensu Binford, 1981) es baja. La poca cohesión de los sedimentos junto con la acción biológica, especialmente de raíces y de mamíferos cavadores, facilitan la migración horizontal y vertical de los materiales, dificultan la diferenciación de unidades estratigráficas discretas y potencian la formación de palimpsestos (Prates, 2008; Prates \& Di Prado, 2013). En NM3, a esta compleja dinámica se sumó la remoción de la capa vegetada, y de parte del depósito de arena, durante las tareas recientes de desmonte y nivelación (Mange et al. 2016), que evitaba que la acción eólica remueva la matriz sedimentaria y mantenía la relativa estabilidad superficial del depósito. De esta manera se desencadenó un proceso rápido de deflación que expuso parte de los entierros y otros materiales arqueológicos del sitio, y que afectó su completitud y disposición espacial. Los restos óseos humanos no afectados directamente por las maquinarias no presentan evidencias de migración vertical u horizontal, ni los restos óseos en general -faunísticos y humanos- muestran señales de alternancia entre entierro y re-exposición. Es interesante 
que esto último contrasta con otros contextos arqueológicos asociados con depósitos eólicos de ambientes fluviales y marinos, que muestran baja preservación de restos orgánicos o grados altos de meteorización en los elementos óseos (entre otros Lovis et al. 2012; Martínez, 2017). Los restos óseos faunísticos de NM3 presentan estadios de meteorización bajos, además de ser abundantes y diversos desde el punto de vista anatómico y taxonómico (Tabla 2). Es decir que, a pesar de la poca integridad espacial y resolución cronológica de los conjuntos, no hay evidencias claras de pérdida de diversidad faunística.

En lo referido a la cronología, los fechados radiocarbónicos disponibles no son suficientes para determinar si la asociación espacial entre restos humanos y otros materiales superficiales derivados de actividades múltiples (faunísticos, artefactos líticos y cerámicos) pudo ser en algún caso producto de la contemporaneidad de eventos residenciales y mortuorios (véase discusión en Prates \& Di Prado, 2013). Como fue señalado, las fechas radiocarbónicas de los restos del Individuo 3 (1.091 \pm 35 años AP) y de los restos de venado $(1.110 \pm 33$ años AP) son estadísticamente indistinguibles, con una media ponderada de $1.101 \pm 24$ años AP. Aun así, las diferencias estadísticamente significativas entre las fechas obtenidas de las muestras de guanaco $(1.430 \pm 70$ años AP) y venado $(1.110 \pm 33$ años $\mathrm{AP})$, implica necesariamente un mínimo de dos ocupaciones residenciales en el sitio. Aunque esto valida la tendencia regional registrada en el área en cuanto a la ocupación residencial recurrente y sistemática de las elevaciones sedimentarias ubicadas en las márgenes de lagunas y/o canales de inundación del río (Prates \& Di Prado, 2013), sólo a través de nuevos fechados sobre restos humanos podrá determinarse si existió también ocupación recurrente para actividades de entierro.

\section{Prácticas mortuorias}

El conjunto mortuorio de NM3 incluye un número mínimo de 12 individuos: cinco articulados total o parcialmente y siete identificados a partir de restos dispersos en superficie. Teniendo en cuenta que sólo fueron recuperados los restos expuestos por deflación luego del trabajo con maquinaria agrícola, es probable que existan otros esqueletos aún sepultados (véase planteos similares en Prates et al. 2010a; Serna \& Prates, 2012). Es importante destacar que todas las inhumaciones, de las que se cuenta con información contextual, son primarias. El conjunto total, incluyendo los restos superficiales, está conformado por varios adultos $(n=8)$ de ambos sexos pero con predominio de masculinos $(n=6) y$, entre los sub-adultos $(n=4)$, también predominan los masculinos $(n=3)$. Más allá de que los cuatro individuos masculinos in situ miran hacia el $\mathrm{E}$ y el femenino hacia el $\mathrm{O}$, no se observa ningún patrón fijo en la posición y orientación de los cuerpos (presentan posiciones decúbito dorsal y lateral, y están orientados al $\mathrm{N}$, al NNO y al SSE) (Tabla 1). La única posible relación entre la ubicación de distintos individuos es la ajustada disposición enfrentada (en espejo) de los Individuos 3 y 4, lo cual implicaría asociación contextual y contemporaneidad.

Otro aspecto interesante sobre el contexto del sitio es el origen de la asociación espacial entre los restos humanos y otros materiales arqueológicos hallados junto a ellos, como artefactos líticos y restos faunísticos. Si bien no es posible descartar la incorporación intencional de estos ítems al depósito mortuorio, las características contextuales son más congruentes con una asociación secundaria entre ambos. Primero, porque los materiales junto a los entierros son desechos tecnológicos y alimenticios abundantes en el conjunto superficial de NM3, y en la mayor parte de los sitios residenciales del área de estudio: valvas de moluscos del género Diplodon y desechos de talla sobre materias primas locales (Prates, 2008; Prates et al. 2010a, 2011). Segundo, porque la práctica de incluir objetos como acompañamiento o ajuar funerario en Norpatagonia ha sido excepcional y ha estado principalmente vinculada a contextos tardíos (La Toma, Peronja et al. 1987; Caepe Malal I, Hajduk \& Biset, 1996; Chimpay, Prates et al. 2016). Y tercero, porque los materiales incorporados como acompañamiento funerario generalmente no son afines o asignables a desechos o residuos, sino objetos enteros y poco frecuentes en contextos domésticos (e.g. adornos y accesorios, valvas de moluscos marinos e instrumentos líticos) (véase discusión en Prates \& Di Prado, 2013; Prates, 
2014 y trabajos allí citados). La asociación espacial entre los depósitos mortuorios (de numerosos individuos) y los desechos derivados de ocupaciones residenciales del mismo sitio se ajusta al patrón general reconocido en la mayoría de sitios del mismo valle: un uso recurrente de los depósitos eólicos elevados para la realización de actividades mortuorias y residenciales (Prates \& Di Prado, 2013).

\section{Explotación de fauna y vegetales}

El rasgo más característico del conjunto faunístico del sitio es la diversidad de especies y el bajo número mínimo de individuos por especie, con excepción de los moluscos de agua dulce. Además, y como ha sido observado previamente (Prates, 2008; Mange et al. 2016), esa diversidad incluye especies procedentes de áreas de captura o nichos diferentes: acuáticas -que sólo habitan ambientes lóticos o lénticos del valle- (e.g. peces y moluscos); ribereñas -que ocupan especialmente ambientes próximos a los cuerpos de agua- (e.g. coipo, rata nutria); especies terrestres del interior del valle (e.g. venado) y especies que ocupan principalmente los sectores de terrazas o planicies altas (e.g. guanaco).

En base a las numerosas huellas de corte y fracturas en estado fresco de huesos largos puede proponerse que los recursos faunísticos explotados principalmente habrían sido carne y médula ósea. Además, se utilizaron elementos óseos y valvas como materia prima para la confección de instrumentos (un retocador sobre hueso largo de mamífero y adornos perforados) y, el caso de megafauna (Mylodontinae), muestra el uso de fósiles posiblemente como objeto con valor simbólico/medicinal, una práctica documentada etnohistóricamente (Casamiquela, 1988; ver discusión en Mange et al. 2016). El mayor volumen alimenticio se habría obtenido de especies terrestres de tamaño grande, sobre todo guanaco (NMI=3), que presenta huellas de corte, impacto y raspado (asociadas con trozamiento, desarticulación y extracción de músculos), fracturas en fresco (relacionadas a la extracción de médula ósea) y combustión (por cocción o descarte en fogones). Otros grandes vertebrados aprovechados fueron O. bezoarticus ( $\mathrm{NMI}=1$ ), que presenta marcas de corte, fractura en fresco y combustión, y Rhea sp.
$(\mathrm{NMI}=1)$ con marcas de corte y termoalteración. También se explotaron mamíferos medianos (D. patagonum y C. villosus) y pequeños ( $G$. leucoblephara), todos ellos con huellas antrópicas. Si bien los moluscos de agua dulce ( $D$. chilensis y Chilina sp.) y peces sólo presentan evidencias de combustión, su posición en un sustrato de origen eólico y su asociación espacial con el resto de los materiales arqueológicos refuerzan la hipótesis de que fueron incorporados al sitio por la acción antrópica. A este conjunto se suman $M$. coypus, que presentan sólo fracturas en estado fresco, y Z. pichiy y Ctenomys sp. que sólo presentan evidencias de combustión.

Si bien en NM3 no se registraron macrorestos vegetales, los micro-restos recuperados del cálculo dental de los Individuos 2, 4 y 5 constituyen evidencias de consumo de algunas especies. El dato más novedoso de la muestra es la presencia de Zea mays en el Individuo 4. No se conocen evidencias etnohistóricas sobre el cultivo de maíz por grupos indígenas locales en contextos no coloniales, ni evidencias arqueológicas de su presencia o consumo. Los registros prehispánicos más meridionales de maíz proceden del análisis de silicofitolitos de residuos alimenticios depositados en vasijas cerámicas del área Andina, cuyos sitios ubicados al Este de los Andes, en los bosques andino lacustres de la actual provincia de Neuquén (Pérez \& Erra, 2011), están prácticamente a la misma latitud que NM3. Algo más al Norte se registraron almidones de esta especie en artefactos de molienda procedentes de la cuenca del río Neuquén (Lema et al. 2012). Aunque la información disponible en NM3 no es suficiente para determinar las causas de la presencia de maíz, su registro no estaría vinculado con la producción in situ. Las hipótesis más plausibles serían que el maíz fue consumido localmente por el Individuo 4 pero que este vegetal fue ingresado al área desde sectores más occidentales (e.g. Noroeste de Patagonia, Chile central o Cuyo), o bien que consumió el maíz en aquellos sectores y se trasladó posteriormente al área (véase interpretaciones similares en Lema et al. 2012; Musaubach \& Berón, 2012, 2016a; Pastor et al. 2012). Aunque la información es aún preliminar, la compatibilidad isotópica de oxígeno del Individuo 4 con el de las aguas del noreste de Patagonia (Serna 2018; Serna et al. 2019), daría en principio mayor apoyo a la primera de las hipótesis. 
Además del maíz se detectaron granos de almidón de Prosopis sp. en las muestras de cálculo dental de los Individuos 4 y 5 , lo que implica la ingesta de sus frutos. Las especies del género Prosopis tienen múltiples usos: maderero, medicinal, tintóreo $\mathrm{y}$, sobre todo, alimenticio (Capparelli, 2007). Las vainas de algunas especies, de sabor dulce, permiten un consumo directo o mediado por procesamiento, tanto de modo estacional como diferido (Capparelli, 2007). Si bien las evidencias directas sobre el uso alimenticio de frutos de algarrobo son escasas en Patagonia (Lema et al. 2012; Capparelli \& Prates, 2015), es diversa la información en fuentes etnohistóricas sobre el consumo de las vainas (crudas y cocidas) y de la elaboración de bebidas fermentadas (Prates, 2009). El consumo combinado de recursos vegetales silvestres $y$ domesticados, como el inferido para el Individuo 4, ha sido observado en otros sitios del gran área pampeano-patagónica, y asociado a grupos cazadores-recolectores que introdujeron el maíz desde circuitos de movilidad e intercambio (Llano \& Barberena, 2013; Heider \& López, 2016; Musaubach \& Berón, 2016a, 2016b).

Por último, en los tres individuos con muestras de cálculo dental se determinóla presencia de fitolitos de Poaceae. El registro de morfotipos asociados a hojas y/o tallos de gramíneas podría implicar la utilización de los dientes como herramientas para manipular fibras vegetales como se registra en otros sitios arqueológicos (Musaubach, 2014). La cantidad de micro-restos silíceos recuperados en el Individuo 4 y sus caracteres morfológicos (predominio de células largas unidas formando placas -espodogramas), son compatibles con el uso de la boca para la elaboración de tecno-facturas. La presencia escasa de fitolitos de gramíneas en el resto de los individuos podría ser resultado de otras prácticas conscientes o inconscientes. Por un lado, podría tratarse de ingesta no intencional de células epidérmicas de hojas y/o tallos ablandados -con fines tecnológicos- en los mismos instrumentos en que se molieron alimentos posteriormente consumidos (e.g. frutos de Prosopis sp.) (véanse casos de multifuncionalidad de instrumentos de molienda en Babot, 2004). Por otro lado, la ingesta intencional -con fines alimenticios- de inflorescencias $\mathrm{y} / \mathrm{o}$ frutos de gramíneas silvestres.
Si bien la proporción de fitolitos en dichos órganos en las especies de poáceas nativas es baja (Babot et al. 2017) pudieron dejar su impronta en el tártaro dental junto con los granos de almidón no identificados.

\section{Materias primas y tecnología lítica}

El conjunto lítico de NM3 muestra tendencias generales similares a las observadas en otros sitios del área. En cuanto a las materias primas, si bien la diversidad y los rasgos macroscópicos sugieren que en su mayoría fueron obtenidas de rodados, esto sólo puede asegurarse para el $48,1 \%$ de los artefactos $(n=65)$ que presenta restos de corteza de este tipo de soporte. En sólo seis se determinó una materia prima diferente a los rodados, cuatro de calcedonia y dos de arenisca. La arenisca pudo ser obtenida de la formación Río Negro (Andreis, 1965; De Ferraris, 1979), disponible en los bordes externos del valle, y las calcedonias en afloramientos ubicados en Somuncurá y entre esta meseta y el río Negro (Prates \& Mange, 2016). En cuanto a los rodados, en el ámbito local hay dos tipos de depósitos de gravas de los que pudieron obtenerse: la formación de Rodados Patagónicos (Cortelezzi et al. 1968; Fidalgo \& Riggi, 1970) y el manto de rodados fluviales del valle del río Negro (Prates, 2008). Si bien el origen primario de estos dos depósitos es la Cordillera de los Andes, ambas fuentes se diferencian por su localización topográfica y por algunas características morfológicas de los rodados. Los Rodados Patagónicos están disponibles en algunos lugares de las mesetas adyacentes al valle (e.g. bordes de bajos) y los fluviales en el interior de la cuenca del río Negro; estos últimos además presentan un tamaño máximo mayor que el de los Rodados Patagónicos (Bonomo \& Prates, 2014). Teniendo en cuenta la distancia desde el sitio a los depósitos de Rodados Patagónicos (más de $5 \mathrm{~km}$ ) y a los de rodados fluviales (disponibles en las inmediaciones del sitio), y considerando la ausencia de evidencias de talla bipolar, utilizada con frecuencia para la talla de rodados pequeños (Curtoni, 1994; Nami, 2000), es probable que en NM3 se hayan explotado principalmente rodados fluviales. La frecuencia de rocas según su composición muestra que para la confección de los instrumentos de 
filo se realizó una selección marcada a favor de las rocas silíceas, que presentan una frecuencia alta entre los instrumentos y muy baja en los depósitos naturales de rodados. Desde el punto de vista tecnológico, tanto el conjunto de artefactos tallados como los de superficies activas presentan características congruentes con una estrategia expeditiva de explotación de rocas disponibles en abundancia en el ámbito local (Andrefsky, 1994): poca estandarización morfológica de los núcleos, baja frecuencia de instrumentos formales, alta frecuencia de artefactos con filos o superficies simples (véase un caso similar en Prates et al. 2010a). En el conjunto se encuentran representadas todas las etapas de manufactura de artefactos mediante talla y los instrumentos producidos están asociados morfológicamente con actividades de corte, raspado y molienda.

\section{CONSIDERACIONES FINALES}

En este trabajo hemos mostrado que el sitio Negro Muerto 3 corresponde a un área de actividades múltiples con correlatos de actividades residencialesy mortuorias. Aunque las características del depósito (de origen eólico) no permitieron diferenciar componentes arqueológicos discretos, fue posible inferir, a partir de la información cronológica, al menos dos eventos de ocupación residencial; datados entre 1426-1171 y 999-924 años cal. AP. Las características de la tecnología lítica y el patrón de explotación de los recursos son congruentes, en líneas generales, con lo observado para el mismo período cronológico en otros sitios del Holoceno tardío final de la región (Prates, 2008; Prates et al. 2010a; Mange et al. 2016). En cuanto a la tecnología lítica: 1) fuerte sello local en las materias primas líticas; 2) uso casi exclusivo de rodados de río y areniscas de la formación Río Negro y predominio de estrategias expeditivas de explotación de las rocas; 3) evidencias de todas las etapas de las secuencias de reducción, uso y descarte. Y en cuanto a los recursos de subsistencia: a) explotación de vertebrados grandes y medianos, como mamíferos mesetarios (guanacos), mamíferos del valle (venados) y aves (ñandú) como principal aporte de biomasa; b) marcado énfasis en la explotación de especies de pequeño porte, con nichos ecológicos asociados a los ámbitos fluviales o ribereños (peces, moluscos, roedores y aves); c) uso de vegetales silvestres para la alimentación, especialmente frutos de Prosopis sp. Sin embargo, hemos detectado en el sitio evidencias novedosas y relevantes mediante el estudio de los micro-restos vegetales, sobre todo las vinculadas con el registro de Zea mays, inferido a partir de silico-fitolitos y granos de almidón en el Individuo 4. La presencia de maíz en el área parece compatible con el ingreso desde regiones occidentales de Norpatagonia y la posible contemporaneidad de los Individuos 3 y 4 (derivada de su asociación contextual), implicaría una cronología de la especie doméstica cercana a los 1000 años AP. Esto último constituye el punto de partida necesario para la exploración más profunda del proceso de dispersión del maíz en lo que probablemente sea su ámbito más marginal de distribución en tiempos prehispánicos.

\section{AGRADECIMIENTOS}

Queremos expresar nuestro agradecimiento a Daniel Cabaza y al Museo Paleontológico de Lamarque (Río Negro) por la oportuna denuncia del hallazgo del sitio y el acompañamiento permanente durante la organización de las campañas. A Gustavo Carus, propietario del Establecimiento Negro Muerto, por su inestimable apoyo y predisposición para que trabajemos dentro de su propiedad. Este trabajo fue realizado con financiamiento de ANPCyT (PICT-2015-3645, dirigido por LP) y CONICET (PIP-244-15, dirigido por LP), y en el marco de un convenio con la Secretaría de Cultura de la provincia de Río Negro.

\section{BIBLIOGRAFÍA}

Andrefsky, W. (1994a). The geological occurrence of lithic material and stone toll production strategies. Geoarchaeology, 9(5), 375-391.

Andreis, R. A. (1965). Petrografía y paleocorrientes de la formación Río Negro. Revista del Museo de La Plata (N.S.), 36 (5), 245-310.

Andrews, P. (1990). Owls, caves and fossils: predation, preservation and accumulation of small mammal bones in caves, with an analysis of the Pleistocene cave faunas from Westbury-sub-Mendip, Somerset. UK: University of Chicago Press.

Apolinaire, E., \& Turnes, L. (2010). Diferenciación específica de 
rheidos a partir de fragmentos de cáscaras de huevo. Su aplicación en sitios arqueológicos del Holoceno Tardío. En M. Berón, L. Luna, M. Bonomo, C. Montalvo, C. Aranda \& M. Carrera Aizpitarte (Eds.), Mamül Mapu: Pasado y Presente desde la Arqueología Pampeana (pp. 215-222). Buenos Aires: Libros del Espinillo.

Aschero, C. (1975). Ensayo para una clasificación morfológica de artefactos líticos. Informe Conicet.

Aschero, C. (1983). Ensayo para una clasificación morfológica de artefactos líticos. Apéndices A y B. MS. Cátedra de Ergología y Tecnología. FILO-UBA.

Aschero, C., \& Hocsman, S. (2004). Revisando cuestiones tipológicas en torno a la clasificación de artefactos bifaciales. Temas de Arqueología. Análisis Lítico, 7-25.

Babot, M. (2004). Tecnología y Utilización de Artefactos de Molienda en el Noroeste Prehispánico. Tesis Doctoral. Tucumán: Facultad de Ciencias Naturales e I.M.L., Universidad Nacional de Tucumán.

Babot, M., Musaubach, M. G., \& Plos, A. (2017). An archaeobotanical perspective in the study of inflorescence phytoliths of wild grasses from arid and semi-arid environments of Argentina. Quaternary International, 434(part B), 129-141.

Behrensmeyer, A. (1978). Taphonomic and ecologic information from bone weathering. Paleobiology, 4(2), 150-162.

Binford, L. (1981). Bones. Ancient Men and Modern Myths. New York: Academic Press.

Brown, A. G. (1997). Alluvial geoarchaeology. Floodplain archaeology and environmental change. Cambridge: Cambridge University Press.

Bonomo, M., \& Prates, L. (2014). La explotación de depósitos secundarios de rodados en el curso medio del río Negro y el litoral marítimo pampeano. Artefactos líticos, movilidad y funcionalidad de sitios en Sudamérica. Problemas y perspectivas, 77-92.

Bozarth, S. (1993). Maize (Zea mays) cob phytoliths from a central Kansas great bend aspect archaeological site. Plains Anthropologist. Journal of the Plains Anthropological Society, 43(166), 279-286.

Buikstra, J. E., \& Ubelaker, D. H. (1994). Standards for data collection from human skeletal remains. Arkansas Archaeological Survey Research Series 44.

Capparelli, A. (2007). Los productos alimenticios derivados de Prosopis chilensis (Mol.) Stuntz y P. flexuosa DC., Fabaceae, en la vida cotidiana de los habitantes del NOA y su paralelismo con el algarrobo europeo. Kurtziana, 33(1), 1-19.
Capparelli, A., \& Prates, L. (2015). Explotación de frutos de algarrobo (Prosopis spp.) por grupos cazadores recolectores del Noroeste de Patagonia. Chungara, 47(4), 549-563.

Casamiquela, R. (1988). En Pos del Gualicho. Viedma: Fondo Editorial Rionegrino.

Cortelezzi, C. R., De Francesco, F. O., \& De Salvo, O. E. (1968). Estudio de las gravas tehuelches en la región comprendida entre el Río Negro y el Río Colorado, desde la costa atlántica hasta la Cordillera. Jornadas Geológicas Argentinas, 3, Buenos Aires, AR.

Curtoni, R. P. (1994). La Experimentación en Arqueología. Estudio de la técnica de reducción bipolar en la localidad arqueológica Tapera Moreira, Cuenca del Río Curacó, Pcia. de La Pampa. Tesis de Licenciatura en Ciencias Antropológicas. Buenos Aires: Facultad de Filosofía y Letras, Universidad Nacional de Buenos Aires.

De Ferraris, C. (1979). Estudio estratigráfico de la Formación Río Negro de la Provincia de Buenos Aires. Sus relaciones con la Región Nordpatagónica. Anales de la Comisión de Investigaciones Científicas, 85-166.

Dembo A., \& Imbelloni, J. (1938). Deformaciones intencionales del cráneo de carácter étnico. Buenos Aires: J. Anesi.

Fernández, F., Del Papa L., Moreira, G., Prates, L., \& De Santis L. (2011). Small mammal remains recovered from two archaeological sites in the middle and lower Negro River valley (Late Holocene, Argentina): taphonomic issues and paleoenvironmental implications. Quaternary International, 245, 135-147.

Fernández-Jalvo, Y., \& Andrews, P. (1992). Small mammal taphonomy of Gran Dolina, Atapuerca (Burgos, Spain). Journal of Archaeological Science, 19, 407-428.

Fidalgo, F., \& Riggi, J. C. (1970). Consideraciones geomórficas y sedimentológicas sobre los Rodados Patagónicos. Revista de la Asociación Geológica Argentina, 25(4), 430-443.

Fisher, A., \& Nacuzzi, L. R. (1992). La destrucción sistemática del paisaje y de los sitios arqueológicos. El caso del Valle de Viedma. Arqueología, 2, 189-229.

Flensborg, G., Serna, A., \& Mange E. (2018). Estudio bioarqueológico del sitio La Toma (curso medio del río Negro, pcia. de Río Negro). Relaciones de la Sociedad Argentina de Antropología, 43, 113-133.

Giovannetti, M., Lema, V., Bartoli, C., \& Capparelli, A. (2008). Starch grains characterization of Prosopis chilensis (Mol.) Stuntz and P. fexuosa DC, and their implication in the analysis of archaeological remains in Andean 
South America. Journal of Archaeological Science, 35, 2973-2985.

González, M. E. (2012). Procesos de Formación en el Registro Bioarqueológico de la subregión Pampa Húmeda y Área Ecotonal Pampa-Patagonia. Tesis Doctoral. Buenos Aires: Facultad de Ciencias Sociales, Universidad Nacional del Centro de la Provincia de Buenos Aires.

Grayson, D. (1991). Alpine faunas from the White mountains, California: adaptative change in the Late Prehistoric Great Basin? Journal of Archaeological Science, 18, 483-506.

Gutiérrez, M. A. (2004). Análisis tafonómicos en el Área Interserrana (Provincia de Buenos Aires). Tesis Doctoral inédita. La Plata: Facultad de Ciencias Naturales y Museo, Universidad Nacional de La Plata.

Hajduk, A., \& Biset, A. M. (1996). El sitio arqueológico Caepe Malal I (cuenca del río Curi Leuvú, Departamento Chos Malal, Provincia de Neuquén). En J. Gómez Otero (Ed.), Arqueología: Sólo Patagonia (pp. 77-87). Puerto Madryn: CENPAT-CONICET.

Heider, G., \& López, L. (2016). El consumo de recursos vegetales silvestres en grupos cazadores recolectores del norte de Pampa Seca (San Luis y Córdoba, Argentina). Mundo de Antes, 10, 73-99.

ICSN - The International Code for Starch Nomenclature. (2011). Recuperado de http://www.fossilfarm.org/ ICSN/Code.html

Korstanje, M. A., \& Babot, M. D. P. (2007). Microfossils characterization from south Andean economic plants. Plants, people and places: recent studies in phytolith analysis. Oxford, UK: Oxbow Books, 41-72.

Lema, V., Della Negra, C., \& Bernal, V. (2012). Explotación de recursos vegetales silvestres y domesticados en Neuquén: Implicancias del hallazgo de restos de maíz y algarrobo en artefactos de molienda del Holoceno Tardío. Magallania, 40(1), 229-247.

Llano, C., \& Barberena, R. (2013). Explotación de especies vegetales en la Patagonia septentrional: el registro arqueobotánico de Cueva Huenul 1 (Provincia de Neuquén, Argentina). Darwiniana, nueva serie, 1(1), 5-19.

Lovis, W. A., Monaghan, G. W., Arbogast, A. F., \& Forman, S. L. (2012). Differential temporal and spatial preservation of archaeological sites in a Great Lakes coastal zone. American Antiquity, 77(3), 591-608.

Lyman, R. (1994). Vertebrate Taphonomy. Cambridge: Cambridge University Press.

Madella, M., Alexandre, A., \& Ball, T. (2005). International code for phytolith nomenclature 1.0. Annals of Botany, 96, 253-260.

Mange, E. (2019). Investigaciones arqueológicas en la margen sur del valle medio-superior del río Negro (provincia de Río Negro). Tesis Doctoral. La Plata: Facultad de Ciencias Naturales y Museo, Universidad Nacional de La Plata.

Mange, E., Prates, L., González Venanzi, L., \& Di Lorenzo, M. (2016). El registro faunístico del sitio Negro Muerto 3 (provincia de Río Negro): tafonomía y patrones de explotación. Comechingonia, 20 (1), 231-254.

Martínez, G. (Ed.). (2017). Arqueología de cazadoresrecolectores del curso inferior del Río Colorado (Provincia de Buenos Aires, Argentina). Aportes al conocimiento de las ocupaciones humanas Pampeano-Patagónicas. Tandil: Facultad de Ciencias Sociales, Universidad Nacional del Centro de la Provincia de Buenos Aires.

Matarrese, A. (2015). Tecnología lítica entre los cazadoresrecolectores pampeanos: los artefactos formatizados por picado y abrasión y modificados por uso en el área Interserrana Bonaerense. Tesis Doctoral. La Plata: Facultad de Ciencias Naturales y Museo, Universidad Nacional de La Plata.

Medina, M., Teta, P., \& Rivero, D. (2012). Burning damage and small-mammal human consumption in Quebrada del Real 1 (Córdoba, Argentina): an experimental approach. Journal of Archaeological Science, 39, 737- 743

Mengoni Goñalons, G. (1999). Cazadores de guanacos de la estepa patagónica. Sociedad Argentina de Antropología, Buenos Aires.

Merchant, V. L., \& Ubelaker, D. H. (1977). Skeletal growth of the protohistoric Arikara. American Journal of Physical Anthropology, 46(1), 61-72.

Moldes de Entraigas, B. del V. (1983). Arqueología y Etnohistoria del bajo curso del río Negro. Presencia hispánica en la Arqueología Argentina, 2, 877-893.

Moreno, F. (1876). Viaje a la Patagonia septentrional. Anales de la Sociedad Científica Argentina, 1, 182-197.

Musaubach, G. (2014). Estudios arqueobotánicos en sociedades cazadoras-recolectoras de ambientes semiáridos: Análisis de microrrestos vegetales en contextos arqueológicos de Pampa Occidental (Argentina). Tesis doctoral. Buenos Aires: Facultad de Filosofía y Letras, Universidad Nacional de Buenos Aires.

Musaubach, M. G., \& Berón, M. A. (2012). Cocinando en ollas en la Pampa Occidental. Datos desde la etnohistoria, el 
registro arqueológico y la arqueobotánica. Las manos en la masa. Arqueologías, antropologías e historias de la alimentación en Suramérica, 599-620.

Musaubach, G., \& Berón, M. (2016a). Food residues as indicators of processed plants in hunter-gatherers' pottery from La Pampa (Argentina). Vegetation History and Archaeobotany, 26(1), 111-123.

Musaubach, G., \& Berón, M. (2016b). El uso de recursos vegetales entre los cazadores-recolectores de la Pampa Occidental Argentina. Latin American Antiquity, 27(3), 397-413.

Nami, H. (2000). Investigaciones actualísticas y piedra tallada. En Actas del III Congreso Argentino de Americanistas, 229-292.

Pastor, S., López L., \& Rivero, D. (2012). Access to maize (Zea mays) \& its manipulation in hunter-gatherer contexts in central Argentina (c 3000-2500 bp). Before Farming, 4, 1-10.

Pérez, A., \& Erra, G. (2011). Identificación de maíz en vasijas recuperadas de la Patagonia noroccidental argentina. Magallania, 39(2), 309-316.

Peronja, A., Sánchez y Juliá, E., \& López, A. (1987). Prospecciones arqueológicas sobre costa de río, con presencia de bivalvos, Provincia de Río Negro. En Actas de las Primeras Jornadas de Arqueología de la Patagonia, 243-248.

Prates, L. (2008). Los Indígenas del Río Negro. Un Enfoque Arqueológico. Buenos Aires: Sociedad Argentina de Antropología.

Prates, L. (2009). El uso de los recursos por los cazadoresrecolectores posthispánicos de Patagonia continental y su importancia arqueológica. Relaciones de la Sociedad Argentina de Antropología, 34, 201-229.

Prates, L. (2014). Crossing the boundary between humans and animals: the extinct fox Dusicyon avus from a huntergatherer mortuary context in Patagonia (Argentina). Antiquity, 88(342), 1201-1212.

Prates, L., \& Marsans, N. (2007). El uso de moluscos de agua dulce (Diplodon chilensis patagonicus) en el sitio Angostura 1 (departamento de General Conesa, Río Negro). Intersecciones en Antropología, 8, 355-359.

Prates, L., \& Di Prado, V. (2013). Sitios con entierros humanos y ocupaciones residenciales en la cuenca del Río Negro (Norpatagonia, Argentina): Diacronía y Multicausalidad. Latin American Antiquity, 24(4), 451-466.

Prates, L., \& Mange, E. (2016). Paisajes de tránsito y estaciones en las planicies y bajos del centro-este de Norpatagonia. Relaciones de la Sociedad Argentina de Antropología, 41(1), 217-236.
Prates, L., Di Prado, V., Mange, E., \& Serna, A. (2010a). Sitio arqueológico Loma de los Muertos. Múltiples ocupaciones sobre un médano del este de Norpatagonia (Río Negro, Argentina). Magallania, 38(1), 163-179.

Prates, L., Flensborg, G. A., \& Bayala, P. (2010b). Caracterización de los entierros humanos del sitio Loma de los Muertos (valle medio del río Negro, Argentina). Magallania, 38(1), 147-162.

Prates, L., Luchsinger, H., Scabuzzo, C., \& Mansegosa, D. (2011). Arqueología y Bioarqueología del sitio La Victoria 5 (Departamento de General Conesa, Río Negro). Intersecciones en Antropología, 12, 155167.

Prates, L., Serna, A., Mange, E., \& de Jong, I. (2016). Expresión material de la interacción entre indígenas y criollos en un sitio funerario del siglo XIX de Norpatagonia (Sitio Chimpay, Río Negro). Intersecciones en Antropología, 17, 35-48.

Piperno, D. (2006). Phytoliths: a Comprehensive Guide for Archaeologists and Paleoecologists. Lanham, Maryland: Altamira Press.

Redford, K., \& Eisenberg, J. (1992). Mammals of the Neotropics. The Southern Cone. Chicago: The University of Chicago Press.

Reichert, E. (1913). The differentiation and specificity of starches in relation to genera, species, etc. Stereochemistry applied to protoplasmic processes and products, and as a strictly scientific basis for the classification of plants and animals. Washington: The Carnegie Institution of Washington.

Scheuer, L., \& Black, S. (2000). Developmental juvenile osteology. London: Academic Press.

Serna, A. (2018). Interacciones humanas en el noreste de Patagonia durante el Holoceno tardio: un enfoque bioarqueológico. Tesis Doctoral. La Plata: Facultad de Ciencias Naturales y Museo, Universidad Nacional de La Plata.

Serna, A., \& Prates, L. (2012). Bioarqueología y cronología del sitio Negro Muerto 2 (Noreste de Patagonia). Magallania, 40(2), 233-245.

Serna, A., \& Romano, V. (2018). Rescates bioarqueológicos en el valle medio del río Negro (Provincia de Río Negro): el potencial informativo del registro altamente perturbado. Revista Argentina de Antropología Biológica, 20(2), $1-12$

Sierpe, V. (2015). Atlas osteológico del guanaco (Lama guanicoe). Punta Arenas: Universidad de Magallanes.

Strobel, P. (1867). Paradero prehistórico in Patagonia. Atti della società Italiana de Scienze Naturali, 10, 167- 
171.

Twiss, P., Suess, E., \& Smith, R. (1969). Morphological classification of grass phytoliths. Soil Science of America Proceedings, 33, 109-115.

White, T., \& Folkens, P. A. (2005). The Human Bones Manual. Londres: Elsevier Academic Press.

Zucol, A. (1996). Estudios morfológicos comparativos de especies de los géneros Stipa, Panicum y Paspalum (Poaceae) de la Provincia de Entre Ríos. Tesis Doctoral. La Plata: Facultad de Ciencias Naturales y Museo, Universidad Nacional de La Plata.

Zucol, A. (1998). Microfitolitos de las Poaceae argentinas: II. Microfitolitos foliares de algunas especies del género Panicum (Paniceae: Panicoideae: Poaceae), en la provincia de Entre Ríos. Darwiniana, 36(1-4), 29-50.

Zucol, A. (1999). Fitolitos de las Poaceae argentinas. IV: Asociación fitolítica de Cortaderia selloana (Danthonieae: Arundinoideae), de la provincia de Entre Ríos (Argentina). Natura Neotropicalis, 30(1-2), 2533.

Zucol, A. (2000). Fitolitos de Poaceae de argentinas: III. Fitolitos foliares de algunas especies del género Paspalum (Paniceae: Panicoideae: Poaceae), en la provincia de Entre Ríos. Darwiniana, 38(1-2), 11-32.

Zucol, A. (2001). Fitolitos: III. Asociaciones fitolíticas de Piptochetium montevidense (Stipeae: Arundinoideae: Poaceae). Una nueva metodología descriptiva. Boletín de la Sociedad Argentina de Botánica, 36(1-2), 69-85. 